\title{
Establishment of an article transfer service for Archives of Plastic Surgery
}

\author{
Younsang Cho \\ Technical Manager, Archives of Plastic Surgery \\ M2community, Seoul, Korea
}

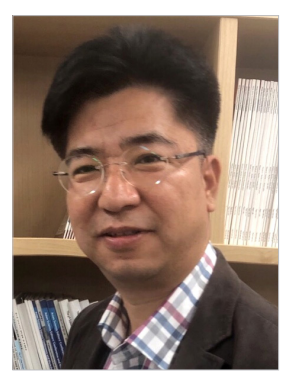

Archives of Plastic Surgery (Arch Plast Surg, APS), the official journal of the Korean Society of Plastic and Reconstructive Surgeons (KSPRS), has been published in English since 2012, during which time papers have been submitted from around the world. However, the editors of APS regret that many high-quality articles with academic value are rejected for not adhering to APS's aims and scopes, or cannot be published simply due to limitations on the number of articles. Therefore, APS editors are promoting the introduction of an article transfer service to address the issues described above and to promote the publication of as many papers of high academic value as possible.

Societies relevant to the KSPRS include the Korean Cleft Palate-Craniofacial Association (KCPCA) and the Korean Society for Aesthetic Plastic Surgery (KSAPS), which publish Archives of Craniofacial Surgery (ACFS) and Archives of Aesthetic Plastic Surgery (AAPS) as their official journals, respectively. In some cases, authors have submitted a paper to APS, only to be notified that it was deemed unsuitable for publication after the peer review process. They then submitted the same paper to ACFS or AAPS. In such a case, the authors must begin the submission process from scratch for a new journal and go through the inconvenience of having the paper peer-reviewed again. Therefore, APS plans to introduce an article transfer service to reduce this inconvenience and to provide a more convenient process to authors who want to submit the same article to another journal in the field of plastic surgery, such as ACFS or AAPS.

The most well-known company that offers an article transfer service is Elsevier [1]. APS will implement the article transfer service as part of its manuscript submission and peer review process. Therefore, if your manuscript is deemed unsuitable for publication in APS, the editor may suggest that you transfer your submission to a more suitable journal, such as ACFS or AAPS, via APS's article transfer service (Fig. 1). If you agree to this, your manuscript will be automatically transferred with no need to reformat or resubmit it. The article transfer service can be applied to APS, ACFS, and AAPS, as they use the same article acceptance and review system. In addition, since all three journals are open-access and peer-reviewed, they can collaborate to implement an excellent article transfer service with allowance for partial adjustments as needed. However, in accordance with the privacy policy, you must agree to disclose your personal information, such as the reviewers' report, your name, your email address, and so on, when you receive the transfer offer. Once you accept the offer, your paper will be transferred automatically to the receiving journal that you select. If a new editorial process is required, the original review comments from APS can be used.

By utilizing this service, you can expect several benefits. First, you will not need to undergo the inconvenient process of resubmission and additional peer review. You will not need to reformat or resubmit your paper to a new journal. Second, the editorial wait time will be shortened, as editors will accept the work done by previous reviewers. Third, you can revise your paper before finalizing submission to a new journal. However, all three of these journals use a double-blind peer review system, and sometimes a reviewer may work for two or more of these journals at the same time. In this case, the paper will be reviewed twice. Additionally, a new reviewer might not agree with the comments made by a reviewer for APS.

APS uses similar manuscript preparation guidelines to those of 


\section{Fig. 1. The process of the article transfer service}

The diagram is the process of the article transfer service for Archives of Plastic Surgery. AAPS, Archives of Aesthetic Plastic Surgery; ACFS, Archives of Craniofacial Surgery.

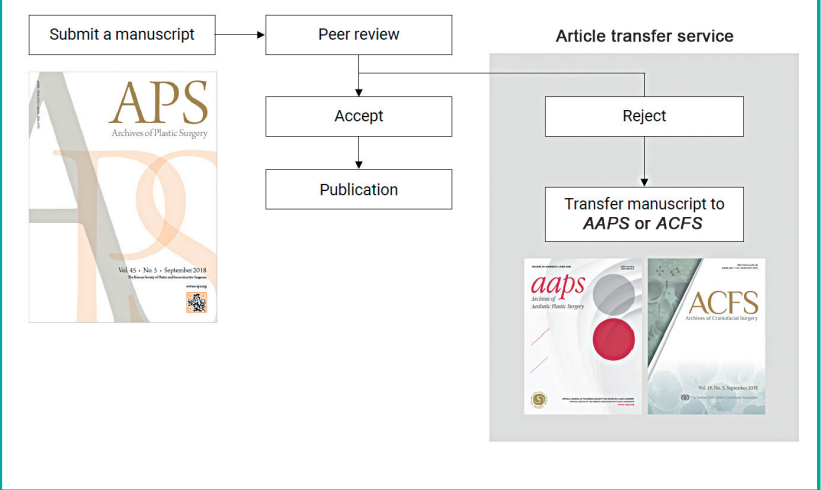

ACFS and AAPS, and only the references are formatted differently. These three journals should unify their article submission policies to make the process more convenient for authors and to improve the efficiency of the editing and publication processes. APS's attempt to introduce an article transfer service is part of its efforts to develop and strengthen journals in the field of plastic surgery. It is important to maintain the system's stability by addressing any issues that occur in the early stages of the introduction of this service. This can be achieved through the consistent interest of, and discussions among, the journals' editors. It is intended that the service will contribute to the development of these three journals, so that they may be known as reliable and trustworthy journals to researchers in the field of plastic surgery.

\section{NOTES}

\section{Conflict of interest}

No potential conflict of interest relevant to this article was reported.

\section{ORCID}

Younsang Cho https://orcid.org/0000-0003-3976-4596

\section{REFERENCE}

1. Elsevier. Article Transfer Service [Internet]. Amsterdam: Elsevier; c2018 [cited 2018 Oct 18]. Available from https:// www.elsevier.com/authors/journal-authors/submit-your-paper/ submit-and-revise/article-transfer-service.

Correspondence: Younsang Cho

M2community, 8th FL, DreamTower, 66 Seongsui-ro, Seongdong-gu, Seoul 04784, Korea Tel: +82-2-2190-7350, Fax: +82-2-2190-7333, E-mail: younsang@m2community.co.kr

Received: 23 Oct $2018 \bullet$ Revised: 7 Nov $2018 \bullet$ Accepted: 8 Nov 2018

pISSN: 2234-6163 • elSSN: 2234-6171

https://doi.org/10.5999/aps.2018.01270 • Arch Plast Surg 2018;45:493-494 